\title{
Sequence Distribution of Segmented Polyurethane-Urea
}

\author{
Atsushi KaJi and Masao Murano \\ Katata Research Center, Toyobo Co., Ltd., \\ 2-1-1 Katata, Otsu, Shiga 520-02, Japan
}

(Received April 16, 1990)

\begin{abstract}
Segmented polyurethane-urea (SPU) elastomer was prepared from polytetramethyleneglycol (PTMG), 4,4'-diphenylmethane diisocyanate (MDI), and ethylenediamine (EDA). The SPU is a kind of block copolymer composed of soft and hard segments. ${ }^{13} \mathrm{C}$ NMR spectra of the SPU were measured and the mean sequence lengths of polyurethane block and polyurea block were estimated from the signals of aromatic carbons. The mean polyurea sequence length was shorter than the hard segment as estimated by X-ray diffraction (Kimura et al.) or by other methods (Suzuki et al.). This polymer was found to be almost a random copolymer. The reactivity of the isocyanate group in MDI decreases slightly when the other side of isocyanate has reacted. The hard segment observed by X-ray diffraction or by other methods might only be the longer fraction of polyurea sequences.

KEY WORDS Polyurethane-urea / Sequence Distribution / Isocyanate / 4,4'-Diphenylmethane Diisocyanate / Reactivity Ratio / ${ }^{13}$ C NMR /
\end{abstract}

Segmented polyurethane-urea (SPU) elastomer is a kind of block copolymer composed of soft and hard segments. The soft segment usually consists of aliphatic polyether or polyester urethane block and the hard segment is a polyurea block. SPU is usually prepared in two-stage reactions as shown in Figure 1. A diisocyanate compound is reacted with a hydroxy terminated prepolymer (I). The amount of the isocyanate compound exceeds that of prepolymer (I) so that the unreacted isocyanate compound remains after the reaction. The resultant polymer (prepolymer (II)) is then extended with a diamine (chain extender). The mechanical properties of SPU depend on (1) the composition of soft and hard segments, (2) the length of soft and hard segments, or in other words, the molecular weight of prepolymer (I) (polyether or polyester) and the sequence length distribution, (3) anomalous linkages (branching, crosslinking), (4) molecular weight of SPU. The hydrogen-bonding in the crystal of the hard segment plays important roles in the elasticity of this polymer. ${ }^{1-3}$ The estimation of the lengths of soft and hard segments is essential for the investigation of SPU. Kimura et al. observed the length of hard segment directly by wide angle $\mathrm{X}$-ray diffraction and by small angle $\mathrm{X}$-ray scattering when the chain extender was 4,4'-diphenylmethanediamine (MDA). ${ }^{4,5}$ They estimated the length of the hard segment composed of the polyurea block to be about four monomer units in the case of the molar ratio of prepolymer (I)/chain extender $=1: 1$. Suzuki et al. measured the length of the polyurea block in a similar SPU (chain extender; hydrazine) by selective degradation. ${ }^{6}$ The length of the polyurea block agreed with the length of the hard segment estimated by Kimura et al. This suggests that the polyurea block is identical to the hard segment.

The length of polyurea block depends on the reactivity ratio of isocyanate groups of diisocyanate compounds. ${ }^{7}$ In the case of $4,4^{\prime}$ diphenylmethane diisocyanate (MDI), the re- 


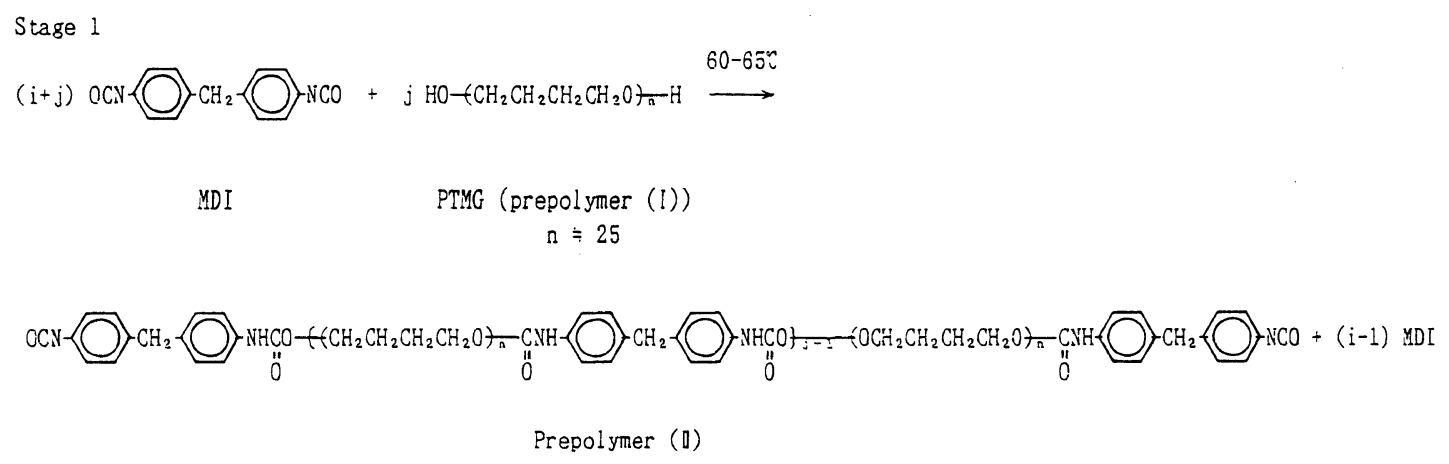

Stage 2

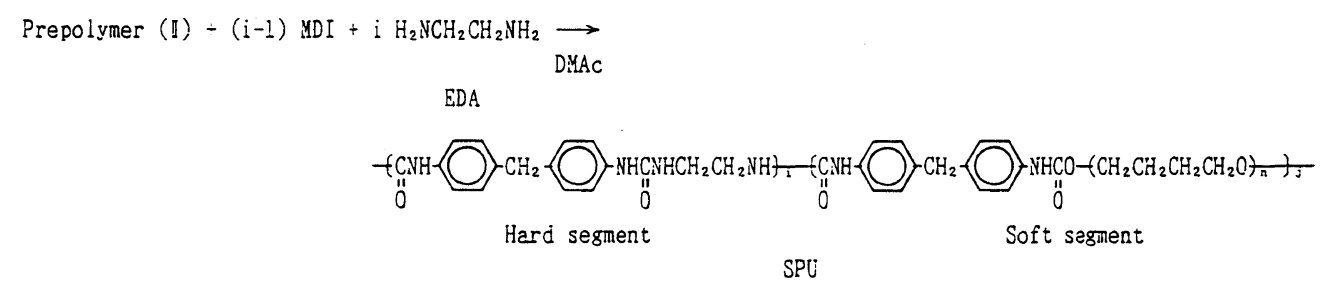

Figure 1. Preparation of segmented polyurethane-urea (SPU).

activity of the isocyanate group is slightly reduced when the other one reacts with a low molecular weight alcohol..$^{8-10}$ If the reactivity of the isocyanate group is also reduced in the reaction with a hydroxyl end group in a polymer such as in prepolymer (I), the molecular weight of the resultant polymer (prepolymer (II) in this case) would be smaller and less free MDIs would remain at this point of the reaction, and in consequence, the length of the polyurea block would be shorter than in case of reactivity increased or unchanged. Suzuki et al. derived the reactivity ratio of the two isocyanate groups from the polyurea sequence lengths by solving kinetic equations and concluded that the reaction of one isocyanate group of MDI enhances the reactivity of the other. ${ }^{6}$

According to the technological development, NMR is the most useful method for the chemical characterization of polymers. There has been a lot of studies elucidating the microstructures of polyurethane $e^{1-14}$ and polyurea, ${ }^{15}$ and the sequence length distribution of polymers ${ }^{16-23}$ by NMR. The mean sequence length of block copolymer measured by using $\mathrm{X}$-ray diffraction is longer than that measured by NMR in general. This is because there must be a distribution of sequence lengths and the X-ray diffraction from the crystalline region can only be observed. Estimation with X-ray diffraction does not provide sufficient information about shorter sequences located in non-crystalline region. The exact number averaged sequence lengths can be elucidated from NMR measurement.

We measured ${ }^{13} \mathrm{C}$ NMR spectra of SPU. We observed the splitting lines due to urethane or urea linkage and measured the sequence lengths of polyurethane and polyurea blocks. In addition, we obtained the reactivity ratio of isocyanate groups in MDI. 


\section{EXPERIMENTAL}

\section{Materials}

SPU was prepared from 4,4'-diphenylmethane diisocyanate (MDI), polytetramethyleneglycol (PTMG; $M_{w} \fallingdotseq 1800$ ), and ethylenediamine (EDA) as shown in Figure 1. PTMG and an excess amount of MDI were mixed under nitrogen atmosphere at $60-65^{\circ} \mathrm{C}$ for $2 \mathrm{~h}$. Then, the reactant prepolymer (II) was dissolved in dimethylacetamide (DMAc) together with EDA at ambient temperature. The polymer was precipitated in water and dried.

Some model compounds were prepared by the reaction of alcohol or amine with isocyanate compounds in DMAc. $n$-Butyl phenylcarbamate (PUT) was prepared from $n$-butyl alcohol and phenyl isocyanate (PHI). Di- $n$-butyl 4,4'-diphenylmethane dicarbamate (MUT) was prepared from $n$-butyl alcohol and MDI. 1-Phenyl-3- $n$-propyl urea (PUA) was prepared from $n$-propyl amine and PHI. 4,4'-Bis(3-n-propylureido)-diphenylmethane
(MUA) was prepared from $n$-propyl amine and MDI.

DMAc was dried by molecular shieves before use. The other materials were used as received.

\section{NMR Measurement}

${ }^{13} \mathrm{C}$ NMR spectra were recorded on a Varian $\mathrm{XL}-300$ spectrometer $\left({ }^{13} \mathrm{C} ; 75.5 \mathrm{MHz}\right)$ at $80^{\circ} \mathrm{C}$. SPU was dissolved in DMAc and dimethylsulfoxide- $d_{6}(c a .10: 1, \mathrm{v} / \mathrm{v})$ at about $25 \%$. Spin-lattice relaxation times $\left(T_{1} \mathrm{~s}\right)$ were measured by inversion recovery method and nuclear Overhauser effects (NOEs) were measured by gated decoupling method. Quantitative measurement was conducted by the gated decoupling method of NOE free mode.

\section{RESULTS AND DISCUSSION}

\section{Assignment of Signals}

The ${ }^{13} \mathrm{C}$ NMR chemical shifts of carbonyl and aromatic carbons of model compounds in DMAc are listed in Table I. These signals are

Table I. ${ }^{13} \mathrm{C}$ NMR chemical shifts (ppm from TMS) of model compounds

\begin{tabular}{cccccc}
\hline & $\mathrm{C}-0$ & $\mathrm{C}-1$ & $\mathrm{C}-2$ & $\mathrm{C}-3$ & $\mathrm{C}-4$ \\
\hline Urethane & & & & & \\
PUT & 153.9 & 139.6 & 118.4 & 128.7 & 122.3 \\
MUT & 153.6 & 137.1 & 118.4 & 128.7 & 135.3 \\
Urea & & & & & 120.6 \\
PUA & 155.3 & 141.1 & 117.3 & 128.4 & 134.0 \\
MUA & 155.2 & 138.8 & 117.5 & 128.4 & \\
\hline
\end{tabular}

Solvent, $N, N$-dimethyl acetamide/DMSO- $d_{6}(c a .90: 10)$; temperature, $50^{\circ} \mathrm{C}$.

Urethane models,

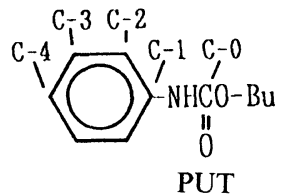

Urea models,

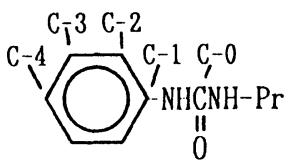

PUA
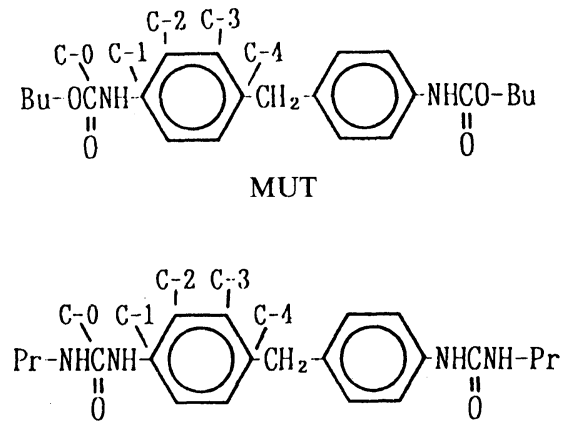

MUA 


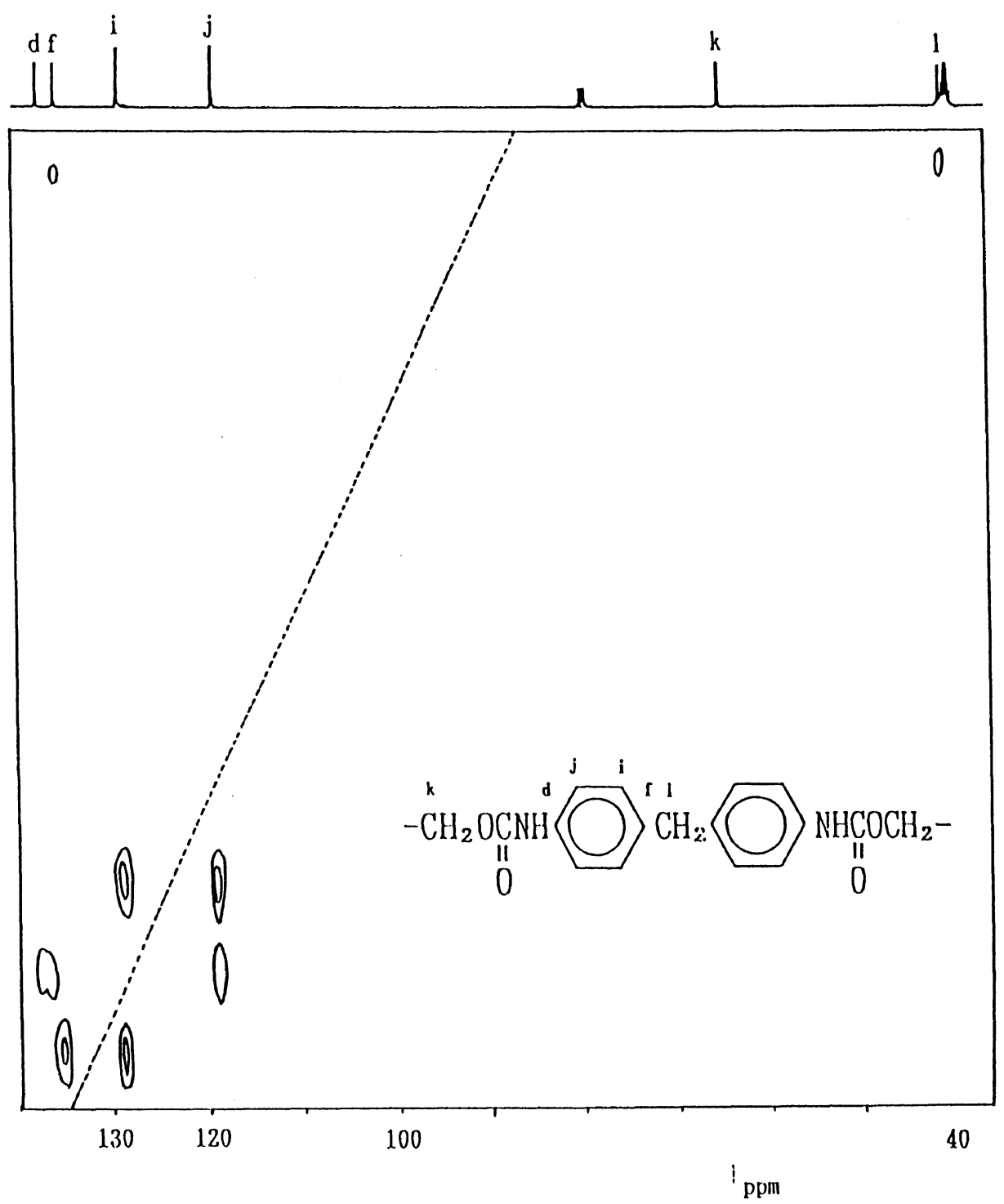

Figure 2. 2D INADEQUATE spectrum of MUT (urethane model compound from MDI) The connectivity of $1\left(\mathrm{CH}_{2}\right)-\mathrm{f}(\mathrm{C}-4)-\mathrm{i}(\mathrm{C}-3)-\mathrm{j}(\mathrm{C}-2)-\mathrm{d}(\mathrm{C}-1)$ can be observed.

assigned according to the empirical rule. In the case of models using PHI (PUT, PUA), the signal due to $\mathrm{C}-1$ carbon (located at about $140 \mathrm{ppm})$ can be distinguished from that of C-4 carbon $(\sim 121 \mathrm{ppm})$ easily. However, the signals of $\mathrm{C}-1$ carbon in MUT and MUA are located close to those of C-4 carbon. The signals of $\mathrm{C}-1$ and $\mathrm{C}-4$ carbons were thus assigned by 2D INADEQUATE spectra. Figure 2 shows the 2D INADEQUATE spectrum of MUT. The signal d (at about $137 \mathrm{ppm}$ ) is due to $\mathrm{C}-1$ carbon of MUT, and signal $\mathrm{f}$ (at about $135 \mathrm{ppm}$ ) is due to $\mathrm{C}-4$ carbon of MUT. The signals of MUA are assigned in the same way. The signals at about $139 \mathrm{ppm}$ and $134 \mathrm{ppm}((\mathrm{c})$ and $(\mathrm{g}))$ are due to $\mathrm{C}-1$ and 
Sequence Distribution of Segmented Polyurethane-Urea

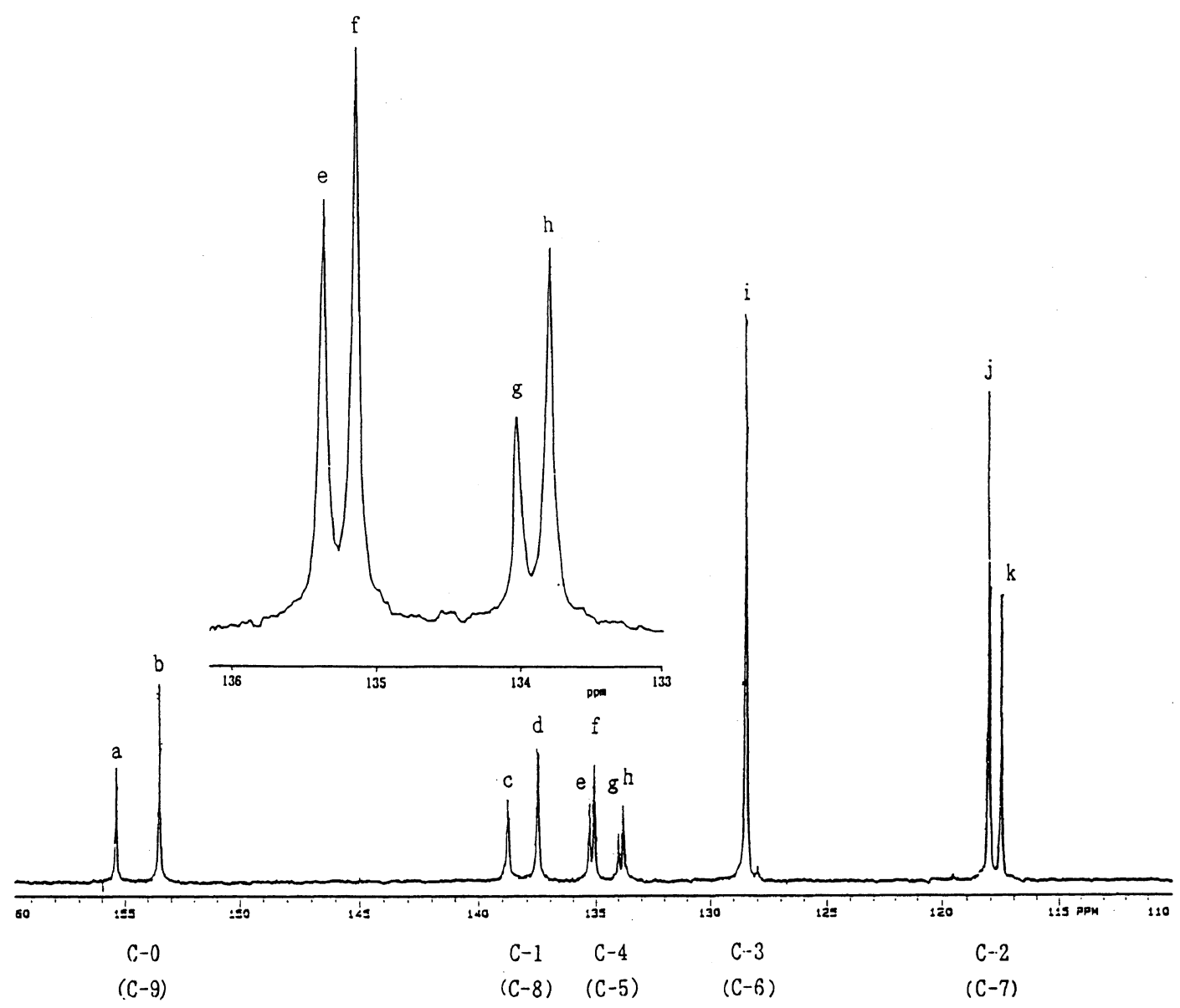

The assignment of the lines

Sequence

$\begin{array}{rrrrr}C-0 & C-1 & C-2 & C-3 & C-4 \\ (C-9 & C-8 & C-7 & C-6 & C-5)\end{array}$

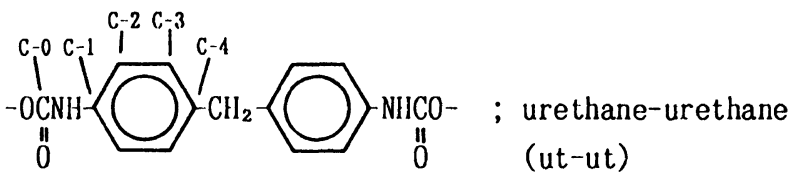

b $\quad d \quad$ j $\quad$ i $\quad f$

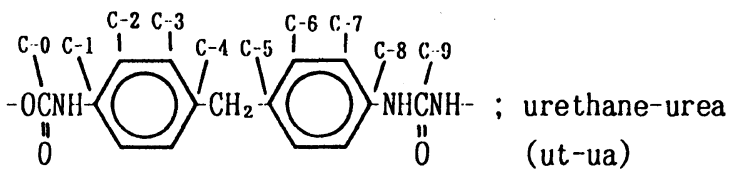

$\begin{array}{lllll}\text { b } & \text { d } & \text { j } & \text { i } & \text { e } \\ \text { a } & \text { c } & \text { k } & \text { i } & \text { h }\end{array}$

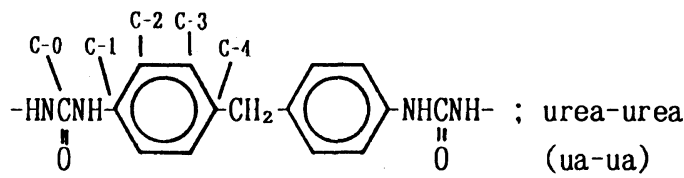

a $\quad$ c. $\quad$ k $\quad$ i $\quad$ g

Figure 3. ${ }^{13} \mathrm{C}$ NMR spectrum of SPU $(110-160 \mathrm{ppm})$. The region of C-4 carbons $(133-136 \mathrm{ppm})$ is expanded. 
C-4 carbons, respectively. The positions of the signals of urethane models are slightly different from those of the corresponding carbons in urea models.

The ${ }^{13} \mathrm{C}$ NMR spectrum of SPU is shown in Figure 3. The signals of C-1, C-2, and C-4 carbons split into two or four lines. It is considered that this splitting depends on whether the isocyanate groups of MDI are turned into the urea bonding or the urethane bonding. The peaks a, c, g, h, i, and k are located close to the signals of MUA (urea model) and the peaks $b, d, e, f, i$, and $j$ to the signals of the MUT (urethane model). The bonding ratio of urea/urethane is estimated from the ratio of these signal intensities. We can calculate the initial molar ratio of MDI/PTMG from the bonding ratio of urea/urethane.

C-1 and C-4 signals split into four lines in the spectrum of SPU. The splitting of C-4 signals is more obvious. The splitting is due to differences of substituents of the other side of diphenylmethane. These signals reveal the sequences of linkages (urethane-urethane (ut-ut), urethane-urea (ut-ua) and urea-urea (ua-ua)). C-9-C-5 are identical to C-0-C-4, respectively in ut-ut and ua-ua sequences because of the symmetric structure. Ut-ua sequence is a junction of polyurethane and polyurea blocks. The signal intensities of lines $\mathrm{e}$ and $\mathrm{h}$ are almost equal. Though there is no exact data for the assignment of the two lines (e and $h$ ), it is not critical for our discussion on sequence lengths. The chemical shifts of these lines are listed in Table II.

\section{Quantitative Analysis}

$T_{1} \mathrm{~s}$ and NOEs of carbonyl and aromatic carbons of SPU were measured before quantitative analysis and are listed in Table III. $T_{1} \mathrm{~s}$ of carbonyl and quaternary carbons are 1.3 to $2.9 \mathrm{~s}$ and those of protonated carbons are 0.3 to $0.4 \mathrm{~s}$. We took $30 \mathrm{~s}$ between pulses for quantitative measurements. The NOEs were about 1.6 and 2.6 for quaternary and
Table II. ${ }^{13} \mathrm{C}$ NMR chemical shifts (ppm from TMS) of SPU

\begin{tabular}{lrrrrr}
\hline Sequences & $\begin{array}{r}\text { C-0 } \\
\text { (C-9 }\end{array}$ & $\begin{array}{r}\text { C-1 } \\
\text { C-8 }\end{array}$ & $\begin{array}{r}\text { C-2 } \\
\text { C-7 }\end{array}$ & $\begin{array}{r}\text { C-3 } \\
\text { C-6 }\end{array}$ & $\begin{array}{r}\text { C-4 } \\
\text { C-5 }\end{array}$ \\
\hline ut-ut & 153.6 & 137.6 & 118.0 & 128.5 & 135.1 \\
ut-ua & & 137.5 & & & 135.6 \\
& & 138.8 & & & 133.7 \\
ua-ua & 155.4 & 138.7 & 117.5 & 128.5 & 134.0
\end{tabular}

Solvent, $N, N$-dimethyl acetamide/DMSO- $d_{6}$ (ca. 90 : 10); concentration, $25 \mathrm{wt} \%$; temperature, $50^{\circ} \mathrm{C}$.

Sequences

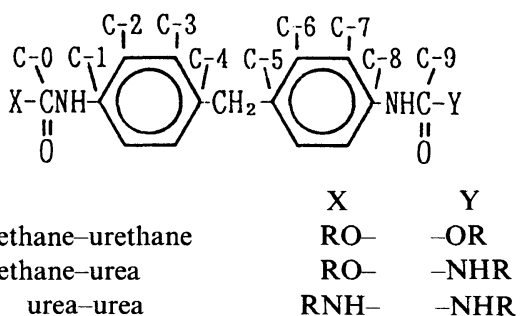

ut-ut urethane-urethan ut-ua, urethane-urea ua-ua urea-urea RNH- - NHR

C-9-C-5 are identical to $\mathrm{C}-0-\mathrm{C}-4$ in symmetric structure.

Table III. $T_{1}$ 's and NOE's of carbonyl and aromatic carbons in $\mathrm{SPU}^{\mathrm{a}}$

\begin{tabular}{cccccc}
\hline \multirow{2}{*}{ Nuclei } & \multicolumn{2}{c}{$T_{1}$ 's } & & \multicolumn{2}{c}{ NOE $^{\mathrm{b}}$} \\
\cline { 2 - 3 } \cline { 5 - 6 } \cline { 5 - 6 } & Urethane & Urea & & Urethane & Urea \\
\hline Carbonyl & 2.3 & 2.9 & & 1.6 & 1.6 \\
C-1 & 2.1 & 1.9 & & 1.6 & 1.5 \\
C-2 & 0.38 & 0.33 & & 2.6 & 2.6 \\
C-3 & $(0.37)$ & $(0.37)$ & & $(2.5)$ & $(2.5)$ \\
C-4 & & & & 1.7 & - \\
ut-ut & 1.6 & - & & 1.7 & 1.7 \\
ut-ua & 1.7 & 1.4 & & 1.7 \\
ua-ua & - & 1.3 & & - & 1.6 \\
\hline
\end{tabular}

a Solvent, $N, N$-dimethyl acetamide/DMSO- $d_{6}(c a .90$ : 10); concentration, $25 \mathrm{wt} \%$; temperature, $50^{\circ} \mathrm{C}$. Since the lines of $\mathrm{C}-3$ in urethane and urea sequences did not split clearly, their $T_{1}$ and NOE could not be measured separately.

${ }^{\mathrm{b}} \mathrm{NOE}=I_{\text {com }} / I_{\text {non }}$, where $I_{\text {com }}$ and $I_{\text {non }}$ are signal intensities measured by the ${ }^{1} \mathrm{H}$-complete decoupling mode and NOE-free mode, respectively.

protonated carbons, respectively. Since the NOEs are not the same even among quaternary carbons, the relative signal areas were measured from spectra taken by the gated de- 
Table IV. Initial feed ratios of MDI/PTMG, molar fractions of three structural units $\left(P_{\mathrm{TT}}, P_{\mathrm{TA}}, P_{\mathrm{AA}}\right)$, urethane-urea ratio, mean sequence lengths $\left(\bar{L}_{n}(\mathrm{ut}), \bar{L}_{n}(\mathrm{ua})\right)$, blockness $(\langle\mathrm{B}\rangle)$, and reactivity ratio of isocyanate groups in MDI (A)

\begin{tabular}{|c|c|c|c|c|c|c|c|c|c|}
\hline \multicolumn{2}{|c|}{ MDI/PTMG } & \multicolumn{3}{|c|}{ Molar fraction } & \multirow{2}{*}{$\frac{\text { Urethane }}{\text { Urea }}$} & \multicolumn{2}{|c|}{ Sequence length } & \multirow{2}{*}{$\begin{array}{c}\text { Blockness } \\
\langle\mathrm{B}\rangle\end{array}$} & \multirow{2}{*}{$\begin{array}{c}\text { Reactivity } \\
\text { ratio } \\
\text { A }\end{array}$} \\
\hline Feed & Observed & $P_{\mathrm{TT}}$ & $P_{\mathrm{TA}}$ & $P_{\mathrm{AA}}$ & & $\bar{L}_{n}(\mathrm{ut})$ & $\bar{L}_{n}(\mathrm{ua})$ & & \\
\hline 1.50 & 1.50 & 0.43 & 0.47 & 0.10 & 2.00 & 2.84 & 1.44 & 1.05 & 0.90 \\
\hline 1.60 & 1.57 & 0.38 & 0.51 & 0.11 & 1.74 & 2.49 & 1.43 & 1.05 & 0.89 \\
\hline 1.65 & 1.64 & 0.36 & 0.50 & 0.14 & 1.56 & 2.43 & 1.55 & 1.06 & 0.88 \\
\hline 1.70 & 1.67 & 0.34 & 0.52 & 0.14 & 1.50 & 2.29 & 1.56 & 1.08 & 0.83 \\
\hline 1.90 & 1.89 & 0.26 & 0.55 & 0.19 & 1.15 & 1.97 & 1.69 & 1.10 & 0.78 \\
\hline
\end{tabular}

coupling method of the NOE free mode.

Let $P_{\mathrm{TT}}, P_{\mathrm{TA}}$, and $P_{\mathrm{AA}}$ represent the molar fractions of urethane-urethane (ut-ut), urethane-urea (ut-ua), and urea-urea (ua-ua) linkages, respectively.

$$
P_{\mathrm{TT}}+P_{\mathrm{TA}}+P_{\mathrm{AA}}=1
$$

$P_{\mathrm{TT}}, P_{\mathrm{TA}}$, and $P_{\mathrm{AA}}$ can be calculated from the relative intensities of $\mathrm{C}-4$ signals. The urethane/urea ratio and feed ratio of $\mathrm{MDI} /$ PTMG are calculated from $P_{\mathrm{TT}}, P_{\mathrm{TA}}$, and $P_{\mathrm{AA}}$ easily.

urethane/urea

$$
=\left(2 \times P_{\mathrm{TT}}+\mathrm{P}_{\mathrm{TA}}\right) /\left(2 \times P_{\mathrm{AA}}+P_{\mathrm{TA}}\right)
$$

$\mathrm{MDI} / \mathrm{PTMG}=($ urethane + urea $) /($ urethane $)$

$$
=2 /\left(2 \times P_{\mathrm{TT}}+P_{\mathrm{TA}}\right)
$$

In the case of the SPU in Figure 3,

$$
\begin{gathered}
P_{\mathrm{TT}}=0.38, \quad P_{\mathrm{TA}}=0.51, \text { and } P_{\mathrm{AA}}=0.11 . \\
\text { urethane/urea }=1.74 \\
\text { MDI } / \mathrm{PTMG}=1.57
\end{gathered}
$$

Several SPUs of different feed ratios of MDI/PTMG were also analyzed and the results are given in Table IV.

The Mean Sequence Lengths of Polyurethane and Polyurea Blocks

The mean sequence lengths of polyurethane and polyurea blocks can be written as eq 4, 5

$$
\begin{aligned}
\bar{L}_{n}(\text { urethane }) & =\left(2 \times P_{\mathrm{TT}}+P_{\mathrm{TA}}\right) / P_{\mathrm{TA}} \\
\bar{L}_{n}(\text { urea }) & =\left(2 \times P_{\mathrm{AA}}+P_{\mathrm{TA}}\right) / P_{\mathrm{TA}}
\end{aligned}
$$

The mean length of the polyurethane sequence was about 2.49 and that of the polyurea sequence was about 1.43 . The results of the other samples are given in Table IV. The polyurea sequence lengths are close to those expected from Bernoullian statistics.

Kimura et al. ${ }^{4,5}$ estimated the polyurea sequence length as about 4 by the X-ray diffraction under stress. This seems too long, taking into account that the MDI/PTMG ratio of the SPU they studied was 2 . The polyurea sequence observed by X-ray diffraction might be the crystalline region in the polyurea sequences.

The polyurea sequence length estimated by Suzuki et al. ${ }^{6}$ was also about 4 (MDI/ PTMG) =2). Although they concluded that the deviation from random copolymer was caused by non-homogeneous reaction, short polyurea sequences might be lost in the recovery.

If the reactivity of the isocyanate group in MDI did not change when the other side of the isocyanate group had reacted with amine, the content of the polyurea sequences in which the number of the monomer units is " $n$ " can be calculated as follows using Bernoullian statistics.

The probability of a polyurea block having $n$ monomer units in its sequence $\left(P\left(L(\text { urea })_{n}\right)\right)$ 
Table V. Probability of urethane or urea linkages belonging to the urethane or urea block whose sequence length is " $n$ "

\begin{tabular}{|c|c|c|c|c|c|c|}
\hline \multirow{2}{*}{$\begin{array}{c}\text { Sequence } \\
\text { length } \\
\text { " } n \text { " }\end{array}$} & \multicolumn{3}{|c|}{ Urethane } & \multicolumn{3}{|c|}{ Urea } \\
\hline & $P\left(L(\mathrm{ut})_{n}\right)$ & $n \times P\left(L(\mathrm{ut})_{n}\right)$ & $P(\mathrm{ut})_{n}$ & $P\left(L(\text { ua })_{n}\right)$ & $n \times P\left(L(\text { ua })_{n}\right)$ & $P(\text { ua })_{n}$ \\
\hline 1 & 0.40 & 0.40 & 0.16 & 0.70 & 0.70 & 0.49 \\
\hline 2 & 0.24 & 0.48 & 0.19 & 0.21 & 0.42 & 0.29 \\
\hline 3 & 0.14 & 0.42 & 0.17 & 0.06 & 0.18 & 0.13 \\
\hline 4 & 0.86 & 0.36 & 0.14 & 0.02 & 0.08 & 0.06 \\
\hline 5 & 0.051 & 0.25 & 0.10 & \multirow{5}{*}{0.01} & \multirow{5}{*}{0.05} & \multirow{5}{*}{0.03} \\
\hline 6 & 0.031 & 0.18 & 0.07 & & & \\
\hline 7 & 0.018 & 0.14 & 0.06 & & & \\
\hline 8 & 0.011 & 0.08 & 0.03 & & & \\
\hline$\geqq 9$ & 0.2 & 0.18 & 0.07 & & & \\
\hline
\end{tabular}

The probability was calculated assuming the reactivity ratio of the isocyanate groups in MDI $(A)=1$ (Bernoulli statistics).

Mean sequence lengths in this SPU, $\bar{L}_{n}(\mathrm{ut})=2.49, \bar{L}_{n}(\mathrm{ua})=1.43 . P\left(L(\mathrm{ut})_{n}\right), P\left(L(\mathrm{ua})_{n}\right)$, molar fraction of urethane or urea block which sequence length is " $n$ ". $n \times P\left(L(\mathrm{ut})_{n}\right), n \times P\left(L(\mathrm{ua})_{n}\right)$, contribution to the mean sequence length.

$P(\mathrm{ut})_{n}, P(\mathrm{ua})_{n}$, probability of urethane or urea linkage belonging to sequence length " $n$ ".

is given by

$$
P\left(L(\text { urea })_{n}\right)=\frac{\left(2 \times P_{\mathrm{AA}}\right)^{n-1} \times P_{\mathrm{TA}}}{\left(2 \times P_{\mathrm{AA}}+P_{\mathrm{TA}}\right)^{n}}
$$

When $P_{\mathrm{AA}}=0.11$ and $P_{\mathrm{TA}}=0.51$, each sequence length is estimated as shown in Table $\mathrm{V}$. The content of the polyurea sequence having longer than 3 monomer units is only $3 \%$ in urea linkages. SPU can be redrawn schematically from the conventional scheme according to Table $\mathrm{V}$ as in Figure $4 \mathrm{~b}$. The mean length of polyurea sequences is much shorter than that in conventional scheme of SPU in Figure 4a. The concept of the hard and soft segments might be reconsidered from this result.

If the hard segment is only composed of longer polyurea sequences in this elastomer, the hard segment content in SPU might be very low. If the short urea components do not contribute to the hard segment and belong to the soft segments, the length between the crosslinking points might be very long. However, the mean urea sequence length $\left(\bar{L}_{n}\right.$ (urea)) defined here is the sequence length of $\left[\mathrm{CONH}-\phi-\mathrm{CH}_{2}-\phi-\mathrm{NHCONHCH}_{2} \mathrm{CH}_{2}-\right.$ $\mathrm{NH}-]_{n},(\phi$, phenylene) then " $n=1$ " means the $-\mathrm{CON}-\phi-\mathrm{CH}_{2}-\phi-\mathrm{NHCONHCH}{ }_{2} \mathrm{CH}_{2} \mathrm{NH}-$
CONH- $\phi-\mathrm{CH}_{2}-\phi-\mathrm{NHCO}-$ sequence containing two urea linkages. The sequence of $n=2$ contains 4 urea linkages. So, these short urea components may also contribute to the hard segment.

\section{Blockness of SPU}

The blockness of SPU $\langle B\rangle$ is defined as follows ${ }^{6}$

$$
\langle\mathrm{B}\rangle=\frac{1}{\left.\bar{L}_{n} \text { (urethane }\right)}+\frac{1}{\bar{L}_{n}(\text { urea })}
$$

The $\langle B\rangle$ value changes according to the blockness of the copolymer.

$0<\langle\mathrm{B}\rangle<1$; block

$$
\text { ( }\langle\mathbf{B}\rangle=0 \text {; homopolymer blend) }
$$

$\langle\mathrm{B}\rangle=1 ; \quad$ random

$1<\langle\mathrm{B}\rangle \leqq 2$; alternating

The $\langle B\rangle$ values of SPUs are also given in Table IV. They are almost independent of the feed ratio of MDI and PTMG. The value of $\langle B\rangle$ is about 1.05 which means that these SPUs are almost random copolymers and have little alternating tendency. Blockness increased slightly with increasing urea content, but the reason 


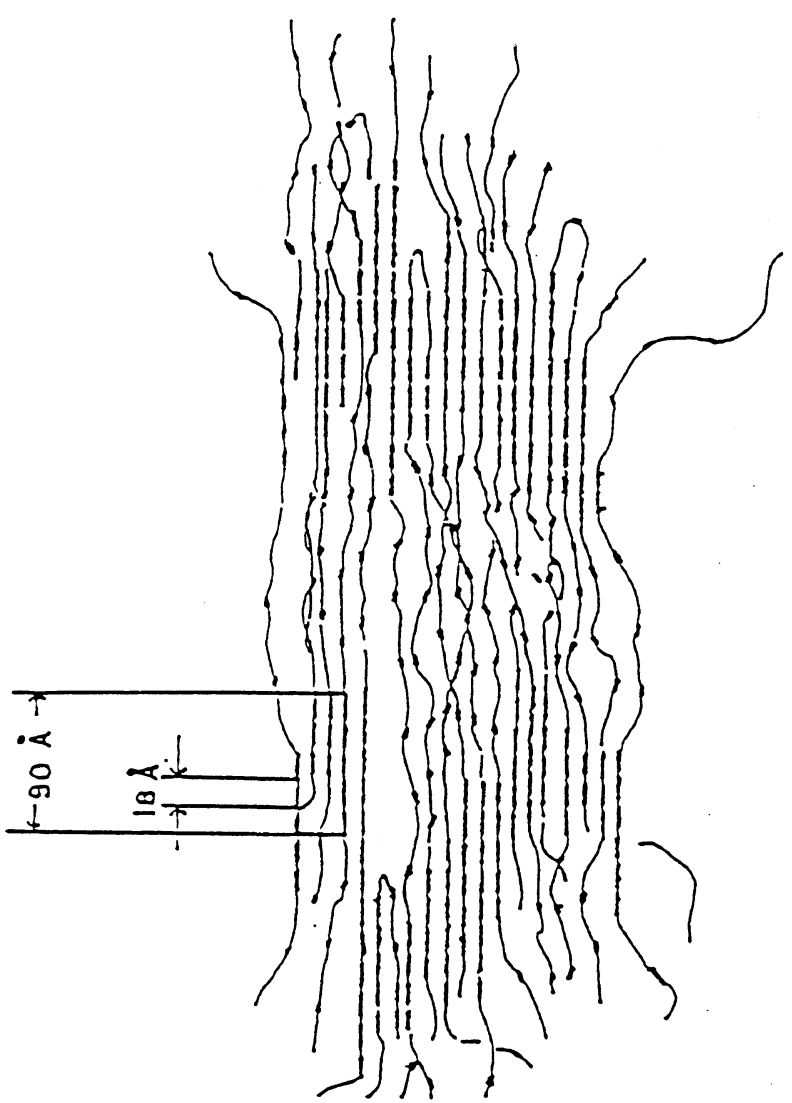

a

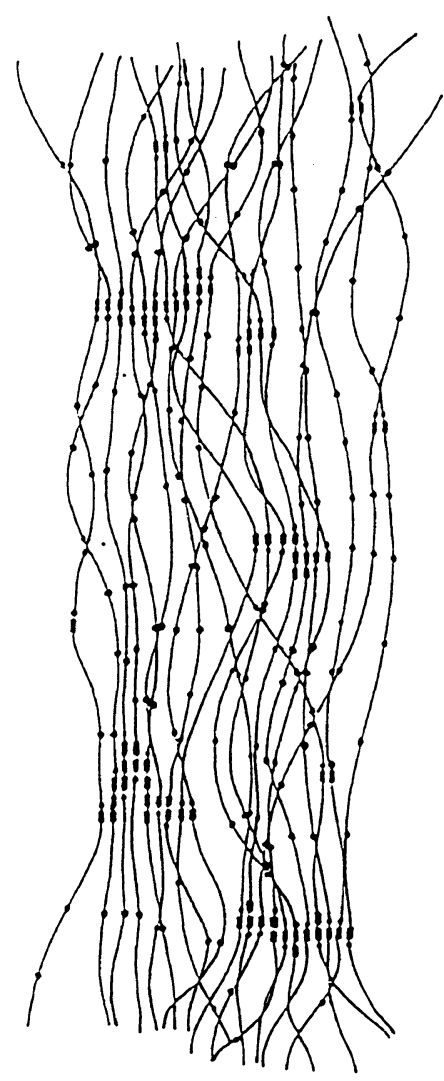

b

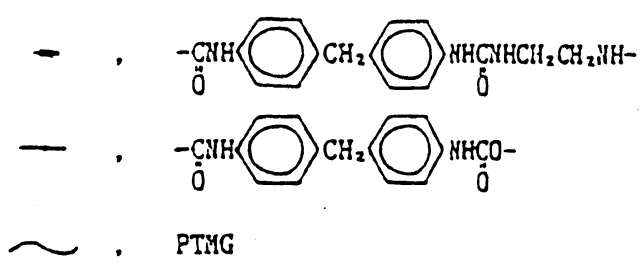

Figure 4. Schematic illustration of stretched and heat set SPU. a, model proposed by Kimura et al. ${ }^{4}$; $\mathrm{b}$, reformed model according to the results of ${ }^{13} \mathrm{C}$ NMR spectroscopy. The sequences are distributed assuming the Bernoullian model as shown in Table IV.

for this is not clear at present.

\section{Reactivity Ratio of Isocyanate Groups of MDI}

The reactivity ratio of isocyanate groups of MDI is defined as follows according to Suzuki et al. ${ }^{6}$

In the prepolymerization, the following ele- mental reactions occur.

$$
\begin{gathered}
\mathrm{OCN}-\phi-\mathrm{CH}_{2}-\phi-\mathrm{NCO}+\mathrm{HO}-\mathrm{R} \stackrel{k_{1}}{\longrightarrow} \\
\mathrm{R}-\mathrm{OCONH}-\phi-\mathrm{CH}_{2}-\phi-\mathrm{NCO}
\end{gathered}
$$

$\mathrm{ROCONH}-\phi-\mathrm{CH}_{2}-\phi-\mathrm{NCO}+\mathrm{HO}-\mathrm{R} \stackrel{k_{2}}{\longrightarrow}$

$\mathrm{R}-\mathrm{OCONH}-\phi-\mathrm{CH}_{2}-\phi-\mathrm{NHCOO}-\mathrm{R}$ (9) 
The reactivity ratio of the two isocyanate groups $(A)$ in MDI is given by

$$
A \equiv k_{2} / k_{1}
$$

The kinetic equations are as follows.

$$
\begin{aligned}
& \mathrm{d}[\mathrm{I}]_{\mathrm{f}} / \mathrm{d} t=-2 k_{1}[\mathrm{I}]_{\mathrm{f}}[\mathrm{OH}] \\
& \mathrm{d}[\mathrm{I}]_{\mathrm{e}} / \mathrm{d} t=\left(k_{1}[\mathrm{I}]_{\mathrm{f}}-k_{2}[\mathrm{I}]_{\mathrm{e}}\right)[\mathrm{OH}]
\end{aligned}
$$

where $[\mathrm{I}]_{\mathrm{f}},[\mathrm{I}]_{\mathrm{e}}$, and $[\mathrm{OH}]$ are the concentrations of the isocyanate group in free MDI, the isocyanate group in the end of polymer, and the hydroxyl group in PTMG, respectively.

The integration of eq. 11 and 12 from time 0 to $T$ gives eq $13(A \neq 2)$.

$$
\begin{aligned}
& \frac{1}{1-A / 2} \ln \frac{(1-A / 2)\left([\mathrm{I}]_{\mathrm{e}} /[\mathrm{I}]_{\mathrm{f}}\right)_{\mathrm{T}}+1 / 2}{(1-A / 2)\left([\mathrm{I}]_{\mathrm{e}} /[\mathrm{I}]_{\mathrm{f}}\right)_{0}+1 / 2} \\
& =-\ln \frac{\left([\mathrm{I}]_{\mathrm{f}}\right)_{\mathrm{T}}}{\left([\mathrm{I}]_{\mathrm{f}}\right)_{0}}
\end{aligned}
$$

Where the boundary conditions are as follows. Time $T$ is the finishing time of stage 1 in Figure 1.

$$
\begin{array}{ll}
\left([\mathrm{I}]_{\mathrm{f}}\right)_{0}=2: & \left([\mathrm{I}]_{\mathrm{f}}\right)_{\mathrm{T}}=2 P_{\mathrm{AA}} \\
\left([\mathrm{I}]_{\mathrm{e}}\right)_{0}=0: & \left([\mathrm{I}]_{\mathrm{e}}\right)_{\mathrm{T}}=P_{\mathrm{TA}}
\end{array}
$$

Thus, then we obtain

$\ln P_{\mathrm{AA}}=\{2 /(\mathrm{A}-2)\} \ln \left\{1-(A-2) \times P_{\mathrm{TA}} / 2 P_{\mathrm{AA}}\right\}$

In the case of $A=2$

$$
\ln P_{\mathrm{AA}}=-P_{\mathrm{TA}} / P_{\mathrm{AA}}
$$

$P_{\mathrm{AA}}$ and $P_{\mathrm{TA}}$ are obtained from ${ }^{13} \mathrm{C}$ NMR spectra and the reactivity ratios $(A)$ are calculated by the least squares method and listed in Table IV.

The values of $A$ ranged from 0.78 to 0.9 for various feed ratio. The reactivity of isocyanate group in MDI decreased slightly when the other side of isocyanate group reacted to form an urethane linkage.

According to Ferstandig and Scherrer, ${ }^{10}$ the reaction rate constant of the first isocyanate in MDI is 3.2 times as large as that of the second isocyanate for the reaction with ethanol at $30^{\circ} \mathrm{C}$. This rate constant ratio $\left(k_{1}^{\prime} / k_{2}\right)$ is not the same as the reactivity ratio we define here. As two isocyanate groups are contained in a free MDI,

$$
k_{1}^{\prime} / k_{2}=2 \times k_{1} / k_{2}=2 \times(1 / A)
$$

Therefore the reactivity ratio of isocyanate groups: $A$ (defined by eq 10 ) is $1 / 1.6$. Ferstandig and Scherrer also reported that the activation energies of the first and second isocyanate reactions $\left(E_{\mathrm{a} 1}, E_{\mathrm{a} 2}\right)$ are 7.2 and $9.4 \mathrm{kcal} \mathrm{mol}^{-1}$, respectively. The reactivity ratio $(A)$ at $60^{\circ} \mathrm{C}$ can be calculated from these activation energies.

The reactivity ratio at temperature $T_{1}\left(A\left(T_{1}\right)\right)$ can be written as

$$
A\left(T_{1}\right)=C \exp \left\{-\left(E_{\mathrm{a} 2}-E_{\mathrm{a} 1}\right) / R T_{1}\right\}
$$

where $C$, the constant for this temperature range; $R$, gas constant. When temperature changes to $T_{2}, A\left(T_{2}\right)$ is represented as

$$
A\left(T_{2}\right)=A\left(T_{1}\right) \exp \left\{\left(E_{\mathrm{a} 2}-E_{\mathrm{a} 1}\right)\left(1 / T_{1}-1 / T_{2}\right) / R\right\}
$$

For $E_{\mathrm{a} 2}-E_{\mathrm{a} 1}=2.2 \mathrm{kcal} \mathrm{mol}^{-1}, R=1.9872 \mathrm{cal}$ $\mathrm{deg}^{-1} \mathrm{~mol}^{-1}, \quad A\left(T_{1}\right)=1 / 1.6, \quad T_{1}=303.15 \mathrm{~K}$, $T_{2}=333.15 \mathrm{~K}$ and thus

$$
A\left(T_{2}\right) \fallingdotseq 0.87
$$

This agrees well with that obtained from the sequence lengths of SPUs. This means that the reaction mechanism of MDI with PTMG is possibly the same as with ethanol. It is reasonable that the mean sequence length of hard segment is short.

\section{CONCLUSIONS}

1) The mean sequence lengths of urethane and urea in SPU can be determined from ${ }^{13} \mathrm{C}$ NMR spectra. The mean sequence lengths of urethane and urea in SPU are shorter than those observed by other authors using X-ray diffraction or other methods. It was found that SPUs are almost random or slightly alternative 
copolymers from the view point of the sequences of urethane and urea linkages.

2) The reactivity of an isocyanate group in MDI decreases slightly when the other isocyanate group in MDI has reacted. Decrease in the reactivity of isocyanate group in MDI observed here agrees with the results of Ferstandig and Scherrer ${ }^{10}$ (estimated from the reaction with ethanol).

3) The hard segment observed by other authors using X-ray diffraction or other methods might be the longer fraction of polyurea sequences. Short polyurea sequences might also contribute to the network system of SPU.

\section{REFERENCES}

1. H. Ishihara, I. Kimura, K. Saito, and H. Ono, $J$. Macromol. Sci-Phys., B10, 591 (1974).

2. J. W. C. Van Bogart, D. A. Bluemke, and S. L. Cooper, Polymer, 22, 1428 (1981).

3. C. B. Wang and S. L. Cooper, Macromolecules, 16, 775 (1983).

4. I. Kimura, H. Ishihara, H. Ono, N. Yoshihara, S Nomura, and H. Kawai, Macromolecules, 7, 355 (1974).

5. H. Ishihara, I. Kimura, and N. Yoshihara, $J$.
Macromol. Sci-Phys., B22, 713 (1983-1984).

6. H. Suzuki and H. Ono, Bull. Chem. Soc. Jpn., 43, 682, 687 (1970).

7. L. H. Peebles, Jr., Macromolecules, 7, 872 (1974).

8. M. E. Baily, V. Kirss, and R. G. Spaunburgh, Ind. Eng. Chem., 48, 794 (1956).

9. J. Burkus and C. F. Eckert, J. Am. Chem. Soc., 80, 5948 (1958).

10. L. L. Ferstandig and R. A. Scherrer, J. Am. Chem. Soc., 81, 4838, (1959).

11. M. Sumi, Y. Chokki, Y. Nakai, and T. Katsuyama, Makromol. Chem., 78, 146 (1964).

12. Y. Chokki, M. Nakabayashi, and M. Sumi, Makromol. Chem., 153, 189 (1972).

13. Y. Chokki, Makromol. Chem., 175, 3425 (1974).

14. H. R. Kricheldorf and W. E. Hull, Makromol. Chem., 182, 1177 (1981).

15. H. R. Kricheldorf, J. Macromol. Sci.-Chem., A14, 959 (1980).

16. M. Murano, Polym. J., 3, 663 (1972).

17. F. W. Yeager and J. W. Becker, Anal. Chem., 49, 722 (1977).

18. R. A. Newmark, M. L. Runge, and J. A. Chermack, J. Polym. Sci., Polym. Chem. Ed., 19, 1329 (1981).

19. R. E. Cais, M. Kometani, and N. H. Salzman, Macromolecules, 19, 1006 (1986).

20. Y. Inoue, A. Kashiwazaki, Y. Maruyama, Y. S. Jo, and R. Chûjô, Polymer, 29, 144 (1988).

21. J. R. Havens and K. B. Reimer, J. Polym. Sci., A, Polym. Chem., 27, 565 (1989).

22. V. A. Nicely, J. T. Dougherty, and L. W. Renfro, Macromolecules, 20, 573 (1987). 